\title{
Impact of environmental problems on human health and economy in the Russian Federation
}

\author{
Kirill Kobzev ${ }^{1 *}$, Nataliya Kobzeva ${ }^{1,2}$, Valeriia Chegge ${ }^{1}$, Maria Balinskaya ${ }^{1}$, \\ Ekaterina Bozhenko ${ }^{1}$, Sirun Saakian ${ }^{1}$, and Dzhuletta Sarkisian ${ }^{1}$ \\ ${ }^{1}$ Don State Technical University, pl. Gagarina, 1, 344003, Rostov-on-Don, Russia \\ ${ }^{2}$ Rostov State Medical University, Nahichevansky av., 29, 344003, Rostov-on-Don, Russia
}

\begin{abstract}
The transition to sustainable development of the Russian Federation as a whole is possible only if sustainable development of all its regions is ensured. This presupposes the formation of an effective spatial structure of the country's economy while maintaining a balance of interests of all constituent entities of the Russian Federation, which predetermines the need to develop and implement programs for the transition to sustainable development for each region, as well as to further integrate these programs in the development of state policy in the field of sustainable development. Problems solved in each region should largely correspond to federal tasks, but at the same time, local specifics must be taken into account.
\end{abstract}

\section{Introduction}

Nature is a set of various natural systems that combine natural structures and formations (subsystems) of a biological, ecological and inert material nature.

Natural systems are able, without prejudice to themselves, to give the products necessary for mankind or to perform work useful for him. This ability, combined with the historical development of management methods, is called natural resource potential.

Nature management is a set of all forms of exploitation of natural resource potential. As an independent section of knowledge, nature management includes elements of natural, social and technical sciences and, in addition to the exploitation of natural resource potential, it deals with issues of nature protection and the effective use of natural components.

The tasks of the economics of nature management, as a science, are reduced to the development of general principles for the implementation of any activity related either to the direct use of nature and its components, or to its changes under the influence of man, and are aimed at ensuring a unified approach to nature as a universal basis of labor.

\footnotetext{
*Corresponding author: 5976765@mail.ru
} 
The object of studying the economics of environmental management is a complex of relationships between natural components, natural conditions of society and its socioeconomic development. Proceeding from this, the subject of environmental economics is the optimization of these relations, the desire to reproduce and preserve the living environment.

The purpose of this work is to consider such issues as environmental problems of Russia, limits on nature use, payments for the use of natural resources, the competence of territories, regions and local governments in the field of environmental and natural environment protection, types of payments for resources. Competence of territories, regions and local authorities in the field of environmental and natural environment protection.

\section{Methods}

Russia is one of the most environmentally polluted countries on the planet. The economic situation in the Russian Federation continues to aggravate the environmental acuteness of the existing negative trends. The decline in production was not accompanied by a similar decrease in the volume of harmful emissions into the environment - in crisis conditions, enterprises save on environmental costs. Due to the deterioration of fixed assets, volley and emergency emissions of harmful ingredients have become more frequent. The condition of the air basin in cities and industrial centers is deteriorating. The list of cities with the highest level of pollution (41 cities) includes: Arkhangelsk, Bratsk, Grozny, Kemerovo, Krasnoyarsk, Moscow, Novosibirsk, etc.

An increase in the level of air pollution is noted not only in cities and adjacent territories, but also in background areas, emissions of large amounts of sulfur dioxide (more than 9 million tons per year) cause acidification of atmospheric precipitation. Areas of high acidity are recorded in the European territory of Russia, as well as in a number of industrial regions with developed non-ferrous metallurgy. The fallout of pollutants on the territory of the Russian Federation is due not only to emissions from its own sources, but also to transboundary transport. Water resources are one of the most important and at the same time the most vulnerable components of the environment. Their rapid change under the influence of economic activity leads to the aggravation of the following problems[1].

Strengthening water management tensions. Water resources are unevenly distributed throughout the country: $90 \%$ of the total annual runoff falls on the basin of the Arctic and Pacific Oceans, and less than $8 \%$ - on the basin of the Caspian and Azov Seas, where over $80 \%$ of Russia's population lives and its main industrial and agricultural potential is concentrated. ... In general, the total water withdrawal for economic needs is relatively small $3 \%$ of the average long-term river flow. However, in the Volga basin, it accounts for 33\% of the total water withdrawal throughout the country, and for a number of river basins, the withdrawal of the average annual flow exceeds the ecologically permissible volumes of withdrawal (Don - 64\%, Terek - 68, Kuban - 80\%, etc.). In the south of the European territory of Russia, practically all water "resources are involved in the national economic activity. Even in the basins of the Ural, Tobolsk and Ishim rivers, water tensions have become a factor, to a certain extent, restraining the development of the national economy. Unacceptably large losses of water. They are large not only on the way from the water source. to the consumer (for example, in 2018, with a total volume of water intake from natural sources of $117 \mathrm{~km}^{3}$, losses amounted to $9.1 \mathrm{~km}^{3}$ ), but also quite significant in industry $-25 \%$ or more (due to leaks in networks, filtration, imperfection of technological processes); in housing and communal services - from 20 to $40 \%$ (due to leaks in residential and public buildings, corrosion and deterioration of water supply networks); in agriculture (over-watering in crop production, overestimated water supply for animal husbandry). 
Surface water pollution. The long-term tendencies of increasing surface water pollution persist. The annual volume of discharged wastewater has not practically changed over the past 5 years and is $27 \mathrm{~km}^{3}$. A huge amount of pollutants comes from wastewater from industry, agriculture and utilities and water bodies. On the territory of the country, almost all water bodies are subject to anthropogenic influence, the water quality of most of them does not meet regulatory requirements. The Volga with its tributaries Kama and Oka will undergo the greatest anthropogenic load. The average annual toxic load on the ecosystems of the Volga is 6 times higher than the load on aquatic ecosystems in other regions of the country. The water quality of the Volga basin does not meet the hygienic, fishery and recreational standards. Due to the congestion and low efficiency of the treatment facilities, the volume of normatively treated wastewater discharged into water bodies is only $8.7 \%$ of the total volume of water to be treated. The MPCs of harmful ingredients in water exceed tens, and sometimes hundreds of times: the waters of the Ural River near the cities of Orel and Orenburg contain iron, oil products, ammonium and nitrate nitrogen, the average annual concentration of which ranges from 5 to 40 MPC; in Primorye, the waters of the Rudnaya River are polluted with boron-containing substances and metal compounds - the concentrations of copper, zinc, boron reach, respectively, 30, 60 and $800 \mathrm{MPC} 1$, etc. The results of checking the quality of water sources showed: only $12 \%$ of the surveyed water bodies can be classified as conditionally clean (background); $32 \%$ are in states of anthropogenic ecological stress (moderately polluted); 56\% - are polluted suitable objects (or their parts), the ecosystems of which are in a state of ecological regression (Fig.1)[2-3].

Mass death of small rivers. A significant part of the urban and rural population lives on the territory of small river basins (up to $100 \mathrm{~km}$ long), which make up $1 / 3$ of the total longterm runoff. Over the past 15-20 years, intensive economic use of winding resources and adjacent lands has led to depletion, shallowing and pollution of rivers. Long-term discharge of wastewater in volumes comparable to the annual volume of runoff has brought to naught the ability of many rivers to self-purify, turning them into open sewers. Uncontrolled withdrawal of water, destruction of water protection zones and drainage of raised bogs led to the mass destruction of small rivers. This process is especially clearly observed in forest-steppe and steppe zones, in the Urals and near the largest industrial centers.

Depletion of reserves and pollution of groundwater. About 1000 foci of groundwater pollution have been identified, $75 \%$ of which are in the most populated European part of Russia. Deterioration in water quality was noted in 60 cities and towns at 80 drinking water intakes with a capacity of more than $1000 \mathrm{~m} 3$ per day. According to expert estimates, the total consumption of polluted water at water intakes is $5-6 \%$ of the total amount of groundwater used for domestic and drinking water supply. The degree of pollution reaches 10 MPC for one or another ingredient - nitrates, nitrites, petroleum products, copper compounds, phenols, etc. The depletion of groundwater is also observed, which manifests itself in a decrease in their levels and the formation of extensive depression funnels, up to $50-70$ $\mathrm{m}$ deep, up to $100 \mathrm{~m}$. In general, the state of the groundwater used is assessed as critical and has a dangerous tendency for further deterioration [4-5]. 


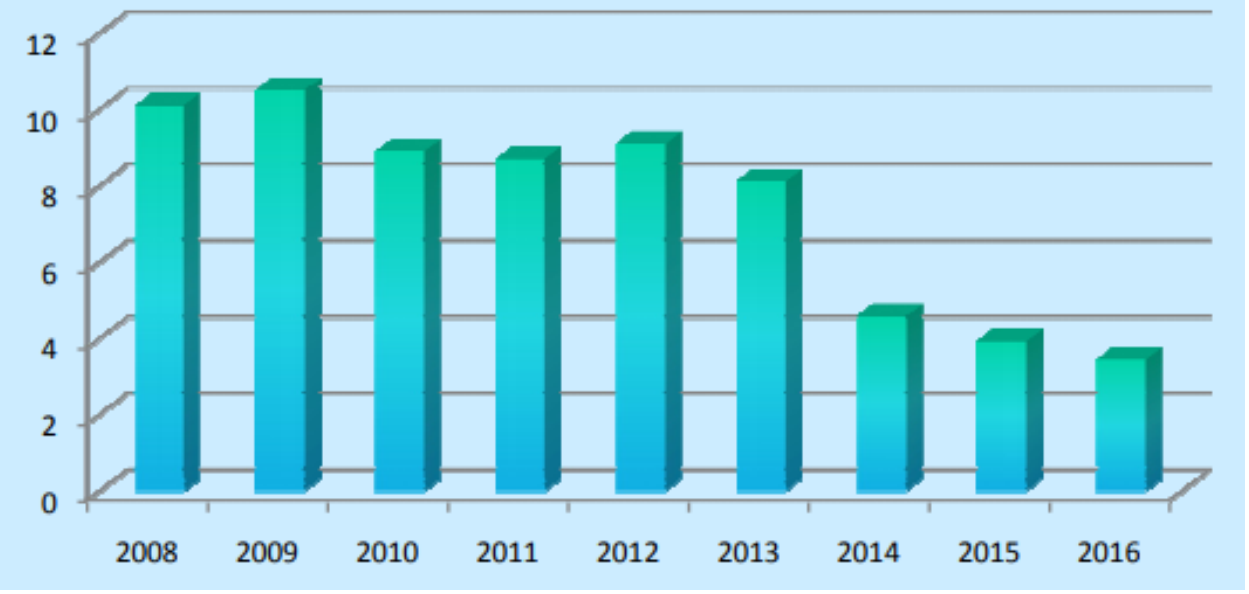

Fig.1 The level of air pollution in the Russian Federation (according to the Air Pollution Index)

Deterioration in the quality of drinking water. The condition of water sources (surface and underground) and centralized water supply systems cannot guarantee the required quality of drinking water (191). More than $50 \%$ of Russians are forced to use water that does not meet standards for various indicators. More than $20 \%$ of drinking water samples do not meet the current standards for chemical indicators and more than $11 \%$ for microbiological indicators, $4.3 \%$ of drinking water samples pose a real danger to public health. The main reasons for the deterioration in the quality of drinking water are: non-observance of the regime of economic activity in the zones of sanitary protection $(17 \%$ of water sources and $24 \%$ of communal water pipelines from surface sources do not have sanitary protection zones at all); the absence in a number of cases of treatment facilities on communal water pipelines (13.1\%) and disinfection installations (7.2\%), as well as secondary water pollution in distribution networks in case of accidents, the number of which increases annually. The danger of the current situation is also evidenced by the annual increase in the number of epidemic outbreaks of acute intestinal infectious diseases, viral hepatitis, caused by the water factor of infection transmission.

Pollution of the seas. All inland and marginal seas of the Russian Federation are experiencing intense anthropogenic pressure both in the water area itself and as a result of economic activities in the drainage basin. The development of abrasion processes is characteristic of the sea coasts, more than $60 \%$ of the coastline experiences destruction, erosion and flooding, which causes significant damage to the national economy and is an additional source of pollution of the marine environment. The burial of radioactive waste in the northern seas is especially dangerous. In recent years, control over the quality of sea waters has somewhat weakened and is carried out under a reduced program due to insufficient funding. Strengthening the negative impact of angropogenic activity on the state and conditions of reproduction of fish stocks. Hydroconstruction, the withdrawal of a large amount of fresh water for irrigation and other economic needs, the operation of water intakes without fish protection devices, water pollution, excess of the catch quota and other factors have sharply worsened the condition and conditions of fish stock reproduction: fish catches are decreasing (a tense situation for the fish industry has developed in the basins rivers: Ob, Irtysh, Yenisei, Kuban The seas of the Far East are characterized by the disappearance of the sardine - ivasi and a reduction in pollock stocks, which is caused by unregulated foreign fishing; the disappearance of valuable fish species occurs, the oppression and death of many 
species of ichthyofauna (in the Volga, the natural spawning grounds of white fish have completely disappeared, only $12 \%$ of sturgeon fish survived; thickets of seaweed (kelp) in some areas of Primorye have disappeared; the incidence of valuable fish species and the accumulation of harmful pollutants in it are increasing (in the muscle tissues of sturgeons, there is an accumulation of chlororganic pesticides, with lei of heavy metals, mercury). The results of the check showed that organic compounds of pguty were found in 156 out of 193 fish samples from various parts of the Vetluga, Cheboksary and Kuibyshevsky reservoirs in concentrations from 0.005 to $1.0 \mathrm{mg} / \mathrm{kg}$ of fish weight[6-8].

The reasons for the ecological crisis of water bodies are associated with the theoretical groundlessness and practical inconsistency of the concept, which has dominated for almost 50 years, based on two false postulates: the inevitability of the formation of wastewater containing industrial waste (in the Federal Republic of Germany, back in the late 1960s, $92 \%$ of enterprises operated on recycled water supply ; at present, the share of recycled water in the total volume of water consumption for industrial purposes in Russia is on average $74 \%$ ); the admissibility of the discharge of wastewater into natural water bodies, which are actually used for additional treatment of wastewater, i.e. as biological treatment facilities. This concept clearly exaggerated the ability of watercourses and reservoirs to purify themselves. It is a powerful mechanism for processing predominantly allochthonous organic matter of natural origin, formed in the reservoir itself and coming from the catchment area. The intake of technogenic substances into natural waters leads to disruption of the functioning of biocenoses and deterioration of water quality.

Recently, there has been a great degradation of land resources. Waste is a serious problem among technogenic loads. On the territory of the country, about 80 billion tons of solid production and consumption wastes have been accumulated in dumps, landfills, storage facilities and unauthorized dumps. Storage facilities, warehouses, burial grounds, landfills and other facilities contain over 1.1 billion tons of toxic and environmentally hazardous industrial waste. In agriculture, there is a problem in two groups of waste: prohibited and worn-out pesticides - there are 13355 tons of pesticides to be neutralized, and animal waste, which annually accumulate 140-150 million tons.

Forest resources. Russia has an area of about 1.2 billion hectares (over $20 \%$ of the world's forest area), and almost $25 \%$ of the world's timber reserves. However, the allowable cut is used irrationally. Cutting of conifers is systematically allowed, and only half of the AAC is used for deciduous tree species. Waste is great during logging and use of timber. During processing, about $20 \%$ of wood is lost. Reforestation work lags behind logging by 1.1 million hectares annually. Fires cause significant damage. There is a process of depletion of forests from air pollution with harmful emissions. Pests and diseases of the forest play a significant role in reducing the resistance of forest plantations. There is an increase in the area of forest pests. The degradation and depletion of vegetation cover, especially of natural forage lands, continues due to high pasture loads and unsatisfactory care for hayfields. So, in the Novosibirsk region, the biological productivity of hayfields has decreased by $2-3$, and the economic - by $3-4$ times. The decrease in the species diversity of flora and fauna is evidence of the general biological depletion of the country. Every tenth species of birds, one in five species of plants and mammals, and one in four species of amphibians and reptiles, 553 species of higher plants and 463 species of animals are endangered. At present, $16-18 \%$ of the country's territory is a zone of ecological crisis. Here deep, and in some cases irreversible damage to natural complexes took place. A characteristic of a similar situation in the regional aspect is presented. One of the main sources of environmental pollution in the republic is the production complex of Volgograd. The most acute problems: degradation of pastures (this process covered $83 \%$ of the territory); deterioration of the quality of drinking water (the salt content in it is 20 times higher than the world standards); the growth of morbidity and mortality of the population due to the deterioration of the liv- 
ing environment (the mortality rate of premature and abnormal babies has increased; neonates have cancer, blood diseases, etc.). $30 \%$ of Russians live in conditions of heightened environmental hazard. It is known that life expectancy in zones of ecological crisis is 10-15 years less than in the country as a whole. The "contribution" of the environmental factor to the deterioration of human health is estimated at the level of $10-30 \%$, while for oncological diseases - about 50\%. Changes in medico-biological indicators of population health indicate a decrease in the birth rate, an increase in mortality and a significant decrease in natural population growth. The trend of growth of indicators of oncological diseases continues. In a matter of years, the life expectancy of Russians; decreased by more than 20 years[9-12].

Hydrosphere: Definition, Composition, Origin and Evolution.

The hydrosphere is the totality of all the water reserves of the Earth. In general, the division of the hydrosphere into the World Ocean, continental waters and groundwater is accepted. Most of the water is concentrated in the ocean, much less in the continental river network and groundwater. There are also large reserves of water in the atmosphere, in the form of clouds and water vapor. Over $96 \%$ of the volume of the hydrosphere is made up of seas and oceans, about $2 \%$ is groundwater, about $2 \%$ is ice and snow, about $0.02 \%$ is surface water on land. Part of the water is in a solid state in the form of glaciers, snow cover and permafrost, representing the cryosphere. Surface waters, occupying a relatively small share in the total mass of the hydrosphere, nevertheless, play an important role in the life of the terrestrial biosphere, being the main source of water supply, irrigation and watering. Moreover, this part of the hydrosphere is in constant interaction with the atmosphere and the earth's crust. The interaction of these waters and mutual transitions from one type of water to another constitute a complex water cycle on the globe. Life on Earth was first born in the hydrosphere. Only at the beginning of the Paleozoic era, the gradual migration of animals and plant organisms to land began.

Origin and evolution. The hydrosphere and its constituent parts, the water cycle, and dynamic phenomena have come a long way of evolution. They have repeatedly changed in terms of mass, the ratio of liquid and solid parts of the water masses involved in the circulation and movement, the speeds and distances of these masses, in terms of the energy contained in them, dissolved gases, solids and organic matter. These changes are recorded in the geological record - the layers of rocks that have formed and are forming now in water bodies - which have not yet been fully deciphered.

Water is so widespread not only on Earth. There is a lot of it in the outer space surrounding us. Thus, the poles of Mars are covered with ice caps; the satellites of Jupiter, Saturn and some other planets are completely ice; comet nuclei are composed of ice (which was experimentally confirmed by the study of Halley's comet); the atmosphere of Venus has a significant amount of water vapor, etc. However, on the surfaces of other planets, water exists only in a solid or vapor state, and on Earth it is predominantly liquid.

According to the data on the rate of radioactive decay of atoms of various elements, the Earth was formed from a cold cloud of gas and dust 4.6 billion years ago. The age of the oldest rocks found today reaches 3.8 billion years, and they retained the imprints of the cell walls of the most ancient unicellular organisms. Mathematical calculations of the general diversity of the genetic code allowed German biochemists to establish its age, which amounted to $3.8 \pm 0.6$ billion years. Therefore, these rocks were deposited in water bodies, where by that time life should have already existed, and one that had time to be actively involved in biogeochemical processes, Therefore, the hydrosphere with liquid water should have appeared even earlier, no later than 4 billion years ago.

Currently, there is no reliable data on the composition of the primary atmosphere and dissolved substances in the primary hydrosphere at the initial stage of their formation. It is believed that from a certain point in time, the atmosphere and hydrosphere began to rapidly 
replenish with gases released during volcanic eruptions and lava outflows, as well as during degassing in reef valleys. The resulting atmosphere was almost completely devoid of oxygen and therefore had a reducing character. Carbon dioxide emitted by volcanoes and released during degassing, together with water vapor, provided greenhouse conditions, which affected the evolution of the Earth[13-15].

The replenishment of the hydrosphere of our planet with water due to the continuous degassing of the mantle material went on constantly, but

with varying intensity. During the period of the "white spot of time", there was a slow growth at the expense of jewelry waters, and then, for about 1 billion years, the hydrosphere grew quite rapidly. In the last 2.5-2 billion years, it has stabilized.

At this time, the mid-oceanic ridges and part of the water was spent on serpentinization2 of the lower layer of the oceanic crust, as a result of which the water that replenished the hydrosphere (together with carbon dioxide) was chemically bound.

After the transformation of the oceanic crust, the ocean mass began to grow again, but about 1 billion years ago it approached the modern one, and its growth rate slowed down greatly. The process of changing the mass of the hydrosphere due to degassing is closely related to the evolution of the Earth's interior and is determined by the growth rate of the dense core of the planet due to the separation of iron compounds in it.

Far from all water coming from the Earth's interior remains in the hydrosphere. One part of the water is spent on the serpentinization of the newly formed portions of the oceanic crust, and the other, together with the sedimentary strata accumulated on the ocean floor, sinks back into the bowels of the Earth in subduction zones. 3 In the process of melting the oceanic crust after it is immersed in the bowels of the Earth, water plays an important role. since water-saturated silicate layers melt at temperatures of about $700^{\circ} \mathrm{C}$, while dry ones at more than $1000^{\circ} \mathrm{C}$.

Throughout the history of our planet, the movement of sea waters from the disappearing oceans to the newly emerging ones. In modern oceans, conveyor-like oceanic crust is generally younger than the oceans themselves. The maximum age of the ocean floor is 150 million years, and usually it is much younger. Today, the overall balance of water inflow and outflow on Earth due to the geological cycle remains positive and the mass of the hydrosphere is continuously increasing.

Life on Earth originated due to the fact that water appeared on it - an amazing substance with anomalous chemical and physical properties. Water molecules are extremely attracted to each other, about 10 times stronger than molecules of other liquids. Therefore, at normal atmospheric pressure, water boils at $100^{\circ} \mathrm{C}$ and melts at $0^{\circ} \mathrm{C}$. If we compare water - hydrogen oxide - with other substances that are compounds of hydrogen with elements that are in the periodic table with oxygen - tellurium, selenium and sulfur, it turns out that the freezing and boiling points of water are unusually high.

It was to be expected that ice would melt at $-90^{\circ} \mathrm{C}$, and water boil at $-70^{\circ} \mathrm{C}$. In this case, all the ice on Earth would melt, and the oceans and seas would boil away. Only the gaseous state of water would become normal in the conditions of our planet. The heat capacity of water is abnormally high; therefore, much more energy is needed to melt ice, heat and evaporate water than for other substances. And the thermal conductivity of water is very low, so the water heats up slowly and cools slowly.

Some amazing properties of water determine many of the most important natural processes occurring on the planet. For example, water has the highest density not at $0^{\circ} \mathrm{C}-$ the melting point, but at $4^{\circ} \mathrm{C}$. Fresh water cooled to temperatures below $4{ }^{\circ} \mathrm{C}$ becomes less dense and therefore remains in the surface layer. This allows the reservoirs not to freeze to the bottom, which saves the life of their inhabitants. When it freezes, water expands and its density in the liquid state is greater than in the solid. Therefore, ice is lighter than water this is another remarkable property of water, which distinguishes it from the vast majority 
of other substances. Thanks to this property, the ice does not sink, does not sink to the bottom of the reservoir, and giant icebergs float in the oceans. Antarctica, Greenland and many other islands in high latitudes are covered with eternal ice. Mountain glaciers form in the mountains at high altitudes. Water has a high surface tension, therefore, raindrops are very resilient and successfully destroy rocks. Due to the peculiarities of its molecular structure, water dissolves various chemical compounds well. Over the long geological history of the planet, the outlines of continents and oceans have changed more than once, large cover glaciers have developed, powerful rivers carried huge masses of destroyed rocks into the seas and oceans.

Water took part in all these processes. Water can flow upward, it rises on its own through the soil capillaries, feeding the soil layer with moisture. Moving up the capillary vessels of grasses and trees, water supplies them with nutrients.

Natural resource use limits. Payment for the use of natural resources. Types of payment for resources.

Limits on natural resource use are a system of environmental restrictions on territories and represent the volumes of maximum use (removal) of natural resources, emissions and discharges of pollutants into the environment and disposal of production waste established for enterprises - users of natural resources for a certain period.

Payment for nature use and its types

Payment for nature use includes payment for natural resources, for environmental pollution and for other types of impact.

Payment for natural resources is charged:

- for the right to use natural resources within the established limits;

- for excessive and irrational use of natural resources;

- for the reproduction and protection of natural resources.

Payment for environmental pollution is charged:

- for emissions, discharges of pollutants, waste disposal and other types of pollution within the established limits;

- for emissions, discharges of pollutants, waste disposal and other types of pollution in excess of the established limits.

Paying for the use of natural resources does not exempt users of natural resources from taking measures to protect the natural environment and compensate for harm caused by an environmental offense.

The law provides for payment for natural resources, including payments for natural resources, environmental pollution and other types of impact.

Payment for natural resources (land, mineral resources, water, forests and other vegetation, fauna), recreational (recreation areas, beaches, etc.) and other natural resources) is charged:

- for the right to use natural resources within the established limits;

- for excessive and irrational use of natural resources;

- for the reproduction and protection of natural resources.

Payments for regulatory and excess emissions and discharges of harmful substances, waste disposal are transferred by enterprises, institutions, organizations in an indisputable manner: $90 \%$ - to special accounts of extra-budgetary state environmental funds, $10 \%$ - to the income of the republican budget of the Russian Federation to finance the activities of territorial government bodies in the field of environmental protection.

Existing economic mechanisms for nature protection are ineffective primarily because they do not create effective incentives for the use of resource and energy saving technologies and do not provide sufficient funds from payments for emissions and discharges, waste disposal and the use of natural resources to finance environmental activities on the required scale ... 
Comparison of the Russian nature management economy with what has developed in countries with a long-developed market economy leads to the conclusion that the cost of natural resources in Russia is artificially underestimated. The cost of a cubic meter of standing timber in Russia is many times lower than in Scandinavia or North America. The same is true for gas, oil, fish, coal, ores, etc.

Payments for nature management implemented in Russia are not based on a real economic assessment of natural resources, objects and impacts. So far, the state does not provide the most important function of the owner of natural resources, without appropriating income from the use of its natural resources. Moreover, the underestimation of the cost of natural resources is beneficial to the army of firms and offices that do not produce, but only resell natural resources and take a disproportionately large share of the profits.

\section{Results}

The jurisdiction of the territories, areas in the field of environmental protection include:

- determination of the main directions of environmental protection and approval of territorial environmental programs;

- accounting and assessment of the natural environment, the state of natural resources, accounting for environmentally hazardous objects, keeping cadastral documentation;

- accounting and assessment of the volume of generated production waste and waste products at enterprises, institutions and organizations located in the region, regardless of their forms of ownership and subordination;

- planning of environmental protection, financing and material and technical support of environmental programs;

- coordination of environmental protection activities of government bodies, enterprises, institutions, organizations, assistance to voluntary cooperation of funds for the implementation of measures for environmental protection;

- coordination of the activities of environmental services of enterprises, institutions, organizations, regardless of the form of ownership and subordination, environmental impact assessment of projects; state environmental control, decision-making on restriction, suspension, termination of activities of facilities that do not meet the requirements of environmental legislation;

- prohibition of construction of environmentally harmful objects;

- granting permits for the right to use the natural environment and its resources, to release and dispose of harmful substances, placement, processing, storage and disposal of waste;

- organization of collection and recovery of industrial and household waste;

- organization of specially protected natural areas;

- organization of environmental education, education and awareness;

- providing the population with the necessary environmental information.

- solution of other issues of environmental protection, referred to the competence of local authorities.

The establishment of normal relations between environmental organizations requires, first of all, the development of special documents on the delimitation of the jurisdiction of various branches of government.

Keeping the environment healthy requires wise management decisions and concrete actions. First of all, it is necessary to green the city, because the oxygen produced by plants gives life to all living things, the absorption of carbon dioxide purifies the atmosphere, and therefore reduces the risk of morbidity among the population. Plants strengthen the soil and prevent the movement of pollutants in it. An important function is noise protection. Along with landscaping, it is necessary to remove the industrial zones still existing here outside 
the city limits, direct the main traffic flows as far as possible from residential buildings, and standardize the emissions of enterprises and vehicles.

\section{Discussion}

The transition to sustainable development of the Russian Federation as a whole is possible only if sustainable development of all its regions is ensured. This presupposes the formation of an effective spatial structure of the country's economy while maintaining a balance of interests of all constituent entities of the Russian Federation, which predetermines the need to develop and implement programs for the transition to sustainable development for each region, as well as to further integrate these programs in the development of state policy in the field of sustainable development. The problems solved in each region should largely correspond to federal tasks, but at the same time it is necessary to take into account local peculiarities, which provides, in particular:

- formation of a regional economic mechanism regulating socio-economic development, including nature management and anthropogenic impact on the environment;

- implementation of nature protection measures in residential and undeveloped areas of cities, other settlements and in suburban areas, including their sanitary cleaning, land reclamation, landscaping and improvement;

- implementation of measures to improve the health of the population, develop social infrastructure, ensure sanitary and epidemiological well-being;

- development of agriculture on the basis of ecologically progressive agricultural technologies adapted to local conditions, implementation of measures to increase soil fertility and protect them from erosion and pollution, as well as create a system of social protection for the rural population;

- reconstruction of the regional industrial system, taking into account the economic capacity of local ecosystems.

Transition to a new system of values. During the transition to sustainable development, mankind will face the need to reassess its goals, redefine the ways to achieve them and develop a new system of principles based on the well-being of future generations.

\section{References}

1. Zolotuhina I 2019 Ways to optimize the prediction of vascular events in patients with acute coronary syndrome and atherosclerotic lesions of the renal arteries, IOP Conference Series: Materials Science and Engineering, 680(1), 012046

2. Kobzev, K. 2020 Studies related to the calculation of the noise. the study of pumping hydraulic systems and the study of the use of an unloading valve in a hydraulic system E3S Web of Conferences 175,05037

3. Zolotuhina I 2019 The use of statistical analysis methods in assessing long-term prognoses in patients with acute coronary syndrome and contrast-induced nephropathy, IOP Conference Series: Materials Science and Engineering, 680(1), 012011

4. Goncharova, Y. 2020 The process of increasing the stable operation of the working body in crank presses E3S Web of Conferences, 164, 03017

5. Kobzev, K. 2020 Learning the basics of a battery pack control system E3S Web of Conferences 164,13006

6. Kobzev, K. 2020 The process of increasing the stable operation of the working body in crank presses E3S Web of Conferences 164,03017 
7. Staseva, E. 2020 Theoretical studies on the calculation of the noise of impact equipment in blacksmith shops E3S Web of Conferences 164,01030

8. Stuzhenko, N.2020 Means and methods of noise protection to reduce the risk of cardiovascular disease in workers E3S Web of Conferences 164,01029

9. Staseva, E 2020 The effect of noise on the human body, in particular, on cardiovascular diseases E3S Web of Conferences 164,01028

10. Il'Ev, A. 2020 Vibration safety to reduce the risk of cardiovascular disease in workers E3S Web of Conferences 164,01025

11. Rybak, A 2020 Simulation of the pump-battery power supply control system based on the unloading machine E3S Web of Conferences 164, 01004

12. Rybak, A.T.2020 Pumping hydraulic systems and the use of an unloading valve in a hydraulic system, E3S Web of Conferences, 175, 05036

13. Ivanovskaya, A.V. 2018 Simulation of drive of mechanisms, working in specific conditions, Journal of Physics: Conference Series 1015(3),032054

14. Demyanov, A. 2019 Skid adjuster for humps E3S Web of Conferences 135, 02020

15. [Gnusov, M 2020 Improving the efficiency of forest fire prevention and suppression with of forest fire machine IOP Conference Series: Materials Science and Engineering 919(3), 032025 